\title{
Desempenho de ovelhas da raça Bergamácia alimentadas com dieta contendo gordura protegida ${ }^{1}$
}

\author{
Rodrigo Martins de Souza Emediato², Edson Ramos de Siqueira², Monalissa de Melo \\ Stradiotto ${ }^{2}$, Sirlei Aparecida Maestá ${ }^{3}$, Heraldo Cesar Gonçalves ${ }^{2}$
}

\author{
1 Projeto de pesquisa financiado pela FAPESP. \\ ${ }^{2}$ FMVZ-UNESP-Botucatu, Departamento de Produção Animal. \\ ${ }^{3}$ CEDRAC-UNESP-Dracena.
}

\begin{abstract}
RESUMO - Objetivou-se com este trabalho avaliar o efeito do uso de gordura protegida na dieta de ovelhas da raça Bergamácia sobre a produção e composição do leite e a dinâmica de peso das ovelhas. Utilizaram-se 77 ovelhas distribuídas em 2 grupos de forma homogênea por ordem de parição e idade, mantidas com uma dieta controle, com silagem de milho e concentrado, ou com a dieta controle contendo gordura protegida (35 g/ovelha.dia) adicionada ao concentrado. As dietas foram isoenergéticas e isoproteicas e continham 16\% PB e 70\% NDT na matéria seca. Durante o dia, os cordeiros eram mantidos com suas mães em pasto, à noite eram separados e retornavam à suas mães após a ordenha matinal; foram desmamados aos 45 dias de idade. As ovelhas, após 48 horas do parto, foram ordenhadas mecanicamente uma vez ao dia, às $7 \mathrm{~h}$, e sua produção de leite foi mensurada diariamente durante 60 dias. Amostras de leite foram coletadas semanalmente para determinação dos teores de proteína e gordura. A dieta com gordura protegida proporcionou maior produção média diária de leite após a desmama dos cordeiros (0,531 vs 0,489 kg/animal.dia). Entretanto, a produção de todo o período não diferiu entre as dietas (0,468 vs 0,453 kg/animal.dia, com gordura protegida e controle, respectivamente). As produções de leite corrigidas para $6,5 \%$ de gordura e para $6,5 \%$ de gordura e 5,8\% de proteína foram semelhantes entre as dietas.
\end{abstract}

Palavras-chave: gordura bypass, leite, ovino, produção de leite, suplementação

\section{Performance of Bergamasca ewes fed diet with bypass fat}

\begin{abstract}
The objective of this study was to observe the effect of using bypass fat in the diet of Bergamasca ewes on milk yield, milk composition and ewe weight dynamics. Seventy seven ewes were distributed in two homogeneous groups, according to lambing order and age fed a control diet with corn silage and concentrate; or with a control diet with bypass fat (35 g/ewe/day) added to the concentrate. The diets were isoenergetic and isonitrogenous, presenting $16 \%$ CP and $70 \%$ TDN on dry matter basis. The lambs stayed with their mothers in pastures during the day and were separated at night. They returned to their mothers after the morning milking and were weaned at 45 days of age. Forty-eight hours after lambing, ewes were machine milked once daily at $7 \mathrm{am}$ and the milk yield was recorded for a period of 60 days. Milk samples were collected weekly to determine the content of milk protein and fat. The bypass fat diet showed a higher daily average milk yield after weaning the lambs (0.531 vs $0.489 \mathrm{~kg} /$ animal.day). However, milk yield throughout the period was not different between the two diets ( 0.468 vs $0.453 \mathrm{~kg} /$ animal.day, for bypass fat and control, respectively). Milk yield corrected to $6.5 \%$ fat and $6.5 \%$ fat and $5.8 \%$ protein were similar in both diets.
\end{abstract}

Key Words: bypass fat, milk, sheep, milk yield, supplement

\section{Introdução}

Segundo a FAO, existem 1,08 bilhão de ovinos no mundo, produzindo cerca de 9 milhões de toneladas de leite (FAOSTAT, 2005), o que representa 1,37\% do total de leite produzido no mundo. Países como Itália, Grécia, Espanha, França e Portugal produzem 39; 29; 15; 11 e 4,6\%, respectivamente, do total do leite ovino da Europa (Haenlein, 2001).
No Brasil, a ovinocultura de leite é uma atividade recente, com poucos dados disponíveis. O leite ovino tem alto valor agregado quando transformado em queijo (OchoaCordero et al., 2002). Assim, deve-se otimizar a produção de leite, uma vez que a produção diária entre as raças de ovelhas varia de 0,06 a 3,50 litros (Bocquier \& Caja, 1999).

No sistema misto de produção de leite, após a única ordenha realizada pela manhã, a ovelha amamenta o seu 
cordeiro até o final do dia, durante os primeiros 30 dias de lactação, comum nos sistemas europeus de produção de leite ovino (Gargouri et al., 1993). Segundo McKusick et al. (2001), apesar de economicamente viável, a principal desvantagem do sistema misto é que o leite obtido no período em que a ovelha ainda amamenta o seu cordeiro apresenta baixo teor de gordura (Fuertes et al., 1998), uma característica indesejável para a produção de queijo (Requena et al., 1999). No sistema misto de produção, durante o período de amamentação, a produção média diária de leite com baixo teor de gordura é menor que no período pós-desmama, possivelmente em decorrência da retenção de leite provocada pelo vínculo mãe-filho, ainda existente neste período (McKusick et al., 1999).

A densidade energética da dieta influencia diretamente a produção e composição do leite em ruminantes. Em ovelhas, o déficit nutricional durante a gestação e o início da lactação ocasiona pico de lactação tardio e de menor amplitude. Por outro lado, dietas de maior densidade energética no início da lactação proporcionam rápido aumento da produção de leite e pico de lactação maior e mais precoce (Bocquier \& Caja, 1999).

A adição de gordura protegida, a qual é inerte no rúmen, pode aumentar a densidade energética da ração e também a ingestão de energia sem comprometer a fermentação de fibras no rúmen (Jenkins \& Palmquist, 1984).

Este trabalho foi realizado para avaliar o efeito da adição de gordura ruminalmente protegida na dieta de ovelhas da raça Bergamácia sobre a produção e composição do leite e a variação no peso vivo.

\section{Material e Métodos}

Utilizaram-se 77 ovelhas da raça Bergamácia distribuídas, 20 dias antes do parto, homogeneamente por idade e ordem de parição em duas dietas: controle (37 animais) e gordura protegida (40 animais). Das quatro ovelhas de cada dieta que pariram gêmeos, foi retirado um filhote, que foi alimentado artificialmente, enquanto o outro foi criado com a mãe.

Durante a gestação, os animais foram mantidos em pastagem de Panicum maximum cv. Tanzânia. Iniciou-se um período de adaptação 20 dias antes da parição, com silagem de milho (Zea mays) e ração concentrada composta de milho moído, farelo de soja, polpa cítrica, farelo de algodão, glúten de milho, ureia, calcário, sal mineral e gordura protegida (Megalac- $\mathrm{E}^{\circledR}$ - Church and Dwight Co., Inc.), na quantidade de $35 \mathrm{~g}$ /ovelha.dia, apenas na dieta com gordura protegida.

As ovelhas receberam concentrado durante todo o período experimental, 0,300 kg durante a ordenha e $0,700 \mathrm{~kg}$ misturado à silagem de milho, fracionado em duas vezes ao dia, imediatamente após a ordenha e às $17 \mathrm{~h}$, totalizando $1 \mathrm{~kg}$ de concentrado/dia. A oferta de silagem foi de $1 \mathrm{~kg}$ MS/ovelha.dia.

As dietas foram isoenergéticas e isoproteicas e continham 16\% PB e 70\% NDT com base na matéria seca. Para alcançar essa igualdade, os níveis de polpa cítrica e farelo de algodão foram mantidos semelhantes. Os animais receberam sal mineral específico à vontade (Núcleo Maxiovinos $40^{\circledR}$ - Maxi Nutrição Mineral Ltda) durante todo o período experimental (Tabelas 1 e 2).

Para ambas as dietas, adotaram-se o sistema misto de produção de leite, de modo que os cordeiros permaneceram com suas mães na pastagem durante o dia e foram separados às $17 \mathrm{~h}$, quando receberam concentrado balanceado de acordo com o NRC (1985) até a desmama (45 dias de idade). Após a ordenha, os cordeiros retornavam às suas mães. As ovelhas, após 48 horas do parto, foram ordenhadas mecanicamente uma vez ao dia, às $7 \mathrm{~h}$ e sua produção de leite foi mensurada diariamente, pelo período de 60 dias. As análises estatísticas foram realizadas com base apenas no leite mecanicamente ordenhado, denominado leite comercial, desconsiderando o leite mamado pelos cordeiros.

Utilizou-se sala de ordenha com plataforma e capacidade para dez ovelhas. A ordenhadeira (Westfalia Tipo RO)

Tabela 1 - Composição dos ingredientes e concentrados utilizados

\begin{tabular}{|c|c|c|c|c|c|c|c|c|}
\hline \multirow[b]{2}{*}{ Nutriente } & \multicolumn{6}{|c|}{ Ingrediente (\%MS) } & \multicolumn{2}{|c|}{ Concentrado (\%MS) } \\
\hline & $\begin{array}{l}\text { Milho } \\
\text { moído }\end{array}$ & $\begin{array}{l}\text { Farelo } \\
\text { de soja }\end{array}$ & $\begin{array}{l}\text { Polpa } \\
\text { cítrica }\end{array}$ & $\begin{array}{c}\text { Farelo } \\
\text { de algodão }\end{array}$ & $\begin{array}{c}\text { Glúten } \\
\text { de milho }\end{array}$ & $\begin{array}{l}\text { Silagem } \\
\text { de milho }\end{array}$ & Controle & $\begin{array}{c}\text { Gordura } \\
\text { protegida }\end{array}$ \\
\hline Matéria seca & 87,12 & 87,51 & 88,98 & 90,85 & 87,91 & 33,52 & 88,00 & 88,65 \\
\hline Proteína bruta & 10,43 & 54,65 & 6,81 & 41,00 & 20,7 & 7,59 & 24,94 & 24,51 \\
\hline Extrato etéreo & 6,78 & 0,89 & 4,22 & 5,54 & 4,24 & 2,41 & 4,16 & 4,36 \\
\hline Matéria mineral & 2,24 & 6,97 & 6,38 & 6,40 & 4,36 & 3,81 & 9,00 & 9,78 \\
\hline Fibra bruta & 6,59 & 6,18 & 15,65 & 14,89 & 13,06 & 25,33 & 12,53 & 12,17 \\
\hline Extratos não-nitrogenados & 73,96 & 31,31 & 66,94 & 32,17 & 57,67 & 60,87 & 45,77 & 41,72 \\
\hline Nutrientes digestíveis totais estimados & 80,75 & 89,35 & 64,30 & 95,07 & 92,31 & 64,18 & 76,63 & 78,76 \\
\hline Fibra em detergente neutro & 25,40 & 14,05 & 24,24 & 33,52 & 50,85 & 47,39 & 28,62 & 26,91 \\
\hline Fibra em detergente ácido & 10,10 & 9,84 & 22,20 & 22,55 & 16,22 & 28,95 & 18,92 & 20,38 \\
\hline
\end{tabular}


Tabela 2 - Formulação dos concentrados

\begin{tabular}{|c|c|c|c|}
\hline \multirow[t]{2}{*}{ Ingrediente } & \multirow[t]{2}{*}{$\mathrm{R} \$ / \mathrm{kg}^{3}$} & \multicolumn{2}{|c|}{ Concentrado (\%MS) } \\
\hline & & Controle & $\begin{array}{l}\text { Gordura } \\
\text { protegida }\end{array}$ \\
\hline Milho moído & 0,420 & 11,70 & 6,18 \\
\hline Farelo de soja & 0,630 & 6,13 & 4,10 \\
\hline Polpa cítrica & 0,350 & 30,15 & 30,23 \\
\hline Farelo de algodão & 0,430 & 29,48 & 29,61 \\
\hline Glúten de milho & 0,320 & 18,11 & 22,54 \\
\hline Uréia & 0,950 & 0,78 & 0,92 \\
\hline Calcário & 0,150 & 0,81 & 0,27 \\
\hline Sal mineral ${ }^{1}$ & 1,000 & 2,83 & 2,84 \\
\hline Gordura protegida ${ }^{2}$ & 1,600 & 0,00 & 3,30 \\
\hline Custo (R\$/kg) & - & 0,41 & 0,45 \\
\hline
\end{tabular}

continha quatro conjuntos de ordenha e linha de leite baixa (120 pulsos/minuto e nível de vácuo de $36 \mathrm{KPa}$ ). Antes de iniciar a ordenha, realizou-se o teste da caneca telada de fundo preto e uma vez por semana o CMT (California Mastitis Test) segundo Schalm \& Noorlander (1957), considerando como positivas as amostras de leite com escore 1+, 2+ e 3+. Em seguida as tetas dos animais foram desinfetadas com solução de iodo glicerinado e, após cerca de 45 segundos, tempo para ação do mesmo, foram secas com papel toalha. Após a ordenha, as ovelhas retornavam com seus cordeiros para amamentá-los e, por este motivo, a desinfecção pós-ordenha não foi realizada até a desmama.

Durante o período experimental, foram observados sete casos de mastite subclínica (9,09\% dos animais). Nas avaliações seguintes, todas as ovelhas com amostras de leite anteriormente reagentes ao CMT não apresentaram mais resultados positivos a esta prova. Nenhum animal apresentou mastite clínica. Não se realizou análise microbiológica para confirmação de mastite subclínica para os casos CMT-positivos.

A ordem de ordenha foi alternada entre as dietas, assim, o lote de animais que foi ordenhado primeiro em um dia, foi o segundo no dia seguinte para evitar influência do período do dia na produção de leite. Uma vez por semana foram coletadas amostras de leite para determinação das concentrações de proteína e gordura, que foram feitas pelo equipamento infravermelho Bentley 2000 (Bentley Instruments, INC. Chaska-MN-USA).

Os pesos das ovelhas foram tomados em balança digital, no pré-parto, a cada 14 dias, à desmama e aos 60 dias pós parto. A produção diária de leite e a porcentagem de gordura e de proteína foram utilizadas para calcular a produção de leite corrigida para 6,5\% de gordura (PL6,5G) e para 6,5\% de gordura e 5,8\% de proteína (PL5,8P), com base nas seguintes equações desenvolvidas por Pulina et al. (1989):

PL6,5G $=$ PL $(0,37+(0,097 \times G))$

PL5,8P $=$ PL $(0,25+(0,085 \times G)+(0,035 \times P))$

em que: $\mathrm{PL}=$ produção de leite $(\mathrm{kg}) ; \mathrm{G}=$ teor de gordura do leite (\%); $\mathrm{P}=$ teor de proteína do leite (\%).

Para esses cálculos, foram utilizados os dados de produção de leite do dia da amostragem de leite para os teores de gordura e proteína.

Os dados experimentais foram analisados como parcelas subdivididas em delineamento inteiramente casualizado, utilizando-se análise de variância conforme o modelo abaixo e o teste de Tukey para diferenças entre médias $(\mathrm{P}<0,05)$. Utilizou-se o programa SAEG 9.0 (UFV, 2005) para análise dos dados, segundo o modelo estatístico: $\mathrm{Y}_{\mathrm{ijk}}=\mu+\mathrm{T}_{\mathrm{i}}+$ $(\mathrm{O} / \mathrm{T})_{\mathrm{ij}}+\mathrm{S}_{\mathrm{k}}+(\mathrm{T} * \mathrm{~S})_{\mathrm{ik}}+\varepsilon_{\mathrm{ijk}}$, em que: $\mathrm{Y}_{\mathrm{ijk}}=$ característica medida na ovelha $\mathrm{j}$, do tratamento $\mathrm{i}$, na semana $\mathrm{k} ; \mu=$ constante; $\mathrm{T}_{\mathrm{i}}=$ efeito do tratamento $\mathrm{i}$, no qual $\mathrm{i}=1$ (controle) ou 2 (gordura protegida); $(\mathrm{O} / \mathrm{T})_{\mathrm{ij}}=$ efeito de ovelha j, dentro de tratamento i (resíduo a); $\mathrm{S}_{\mathrm{k}}=$ efeito de semana $\mathrm{k}$, de modo que $\mathrm{k}=1,2, \ldots 9 ;\left(\mathrm{T}^{*} \mathrm{~S}\right)_{\mathrm{ik}}=$ efeito de interação tratamento $\times$ semana; $\varepsilon_{i j k}=$ erro aleatório referente à observação $\mathrm{Y}_{\mathrm{ijk}}$.

As correlações entre características foram calculadas corrigindo os dados para efeito de tratamento e testadas pelo teste t $(\mathrm{P}<0,05)$, de acordo com Stell \& Torrie (1980).

\section{Resultados e Discussão}

Não houve influência das dietas sobre a produção de leite até a 7 a semana de lactação (Tabela 3), provavelmente em decorrência do sistema de produção utilizado, no qual a manutenção dos cordeiros com suas mães levou à retenção de leite e, apesar de a desmama ter sido à $6 \underline{\text { a }}$ semana, o efeito da dieta só foi observado uma semana depois. Segundo Marnet \& Mckusick (2001), o vínculo mãefilho parece ser um forte regulador de secreção de ocitocina. A ejeção contínua do leite depende da presença de elevada concentração de ocitocina durante toda a ordenha e qualquer falha no processo de ejeção do leite pode interromper sua remoção (Bruckmaier \& Blum, 1998).

Marnet \& Negrão (2000) verificaram que a concentração de ocitocina plasmática foi maior durante a amamentação dos cordeiros em comparação à ordenha mecânica, fato atribuído, não a uma ineficiência da glândula pituitária, mas provavelmente, a um efeito do comportamento materno, pelo qual a inibição do reflexo da ejeção do leite ocorre devido ao estresse e à consequente vasoconstrição, ausente quando as ovelhas amamentam seus cordeiros.

Considerando a produção média diária de leite comercial de todo o período experimental, não houve diferenças entre 
as dietas, mas houve entre semanas, embora as médias semanais tenham diferido apenas a partir da $7 \underline{a}$ semana de lactação. No período pós-desmama, a produção média diária de leite foi $8,5 \%$ maior ( 0,531 vs $0,489 \mathrm{~kg} /$ animal.dia) entre os animais que receberam gordura protegida na dieta.

Ovelhas da raça Sarda alimentadas com 4\% de gordura protegida na dieta a partir da $10^{\underline{a}}$ semana de lactação apresentaram maior produção de leite e persistência de lactação após a 6a semana experimental (Rossi et al., 1991). Com a raça Assaf recebendo 5,6\% de gordura protegida, Sklan (1992) encontrou significativo aumento da produção de leite (1,36 vs $1,59 \mathrm{~kg} / \mathrm{dia})$.

O pico de lactação da ovelha ocorre em média entre a 2 $2^{\underline{a}}$ e a 4 a semana de lactação (Church, 1984). Neste trabalho, com a desmama aos 45 dias, o efeito inibitório da presença do cordeiro sobre a produção de leite retardou o pico de produção de leite comercial para a 7a semana (após a desmama) e somente permitiu a expressão do potencial de produção das ovelhas neste período, prejudicando a produção total de leite comercial.

A produção de leite dos animais mantidos com a dieta controle apresentou redução mais acentuada após a desmama (Tabela 3), comprovando possível persistência de lactação entre os animais que receberam gordura protegida na ração. Quando as produções foram ajustadas para 6,5\% de gordura e 5,8\% de proteína, não houve diferenças entre as dietas. Após a desmama, continuou-se com apenas uma ordenha diária, o que pode ter prejudicado o real potencial de produção de leite das ovelhas e levado ao encurtamento da lactação, uma vez que, após a 7ạ semana de lactação, ambas as dietas ocasionaram redução da produção de leite. Esse comportamento provavelmente foi promovido pela morte das células secretoras dos alvéolos, em virtude do aumento da pressão intramamária com o acúmulo do leite ao longo do dia.

De acordo com Gargouri et al. (1993), mais leite comercial é produzido quando as ovelhas são ordenhadas duas vezes ao dia, ou no mínimo uma vez, e durante a amamentação dos cordeiros nos primeiros 30 dias de lactação. Após a desmama, observou-se aumento médio diário de pouco mais de 100 g/ovelha, o que não representa a capacidade máxima de produção de leite das ovelhas durante 24 horas, mas sua capacidade máxima de armazenamento, pois, com o fim do efeito inibitório sobre a produção de leite, esperava-se aumento maior na produção de leite comercial, uma vez que os cordeiros mamam mais de $100 \mathrm{~g}$ de leite/dia. De acordo com Degen \& Benjamin (2003), cordeiros da raça Awassi ingerem cerca de 1,3 L de leite/dia ou 5,2 L de leite/kg PV ganho.

O efeito da suplementação da gordura protegida foi examinado por Chilliard \& Bocquier (1993), Caja \& Bocquier (2000) e Bocquier \& Caja (2001), que, após ampla revisão, reportaram que o uso da gordura protegida aumenta a produção de leite de vacas leiteiras e nem sempre eleva a produção de cabras e ovelhas, no entanto, o inverso ocorre com relação ao teor de gordura no leite.

A produção de gordura e o teor e a produção de proteína não diferiram entre as dietas durante todo o período experimental (Tabela 4). Resultados similares foram observados com Mckusick et al. (1999) com ovelhas sob suplementação com gordura protegida (100 g/dia) durante o período de amamentação.

Antes da desmama, não houve diferença no teor de gordura do leite entre as dietas (semanas 1 a 6 ), o que pode estar relacionado à distribuição da gordura no úbere da ovelha, pois, segundo Labussière (1969), essa distribuição

Tabela 3 - Produção de leite real e corrigida para 6,5\% de gordura e para 6,5\% de gordura e 5,8\% de proteína (PL5,8\%)

\begin{tabular}{|c|c|c|c|c|c|c|c|}
\hline & \multirow[b]{3}{*}{ Sem $^{1}$} & \multicolumn{6}{|c|}{ Produção de leite } \\
\hline & & \multicolumn{2}{|c|}{ Real (kg/animal.dia) } & \multicolumn{2}{|c|}{$\begin{array}{l}\text { Corrigida para 6,5\% } \\
\text { de gordura (kg/animal.dia) }\end{array}$} & \multicolumn{2}{|c|}{$\begin{array}{l}\text { Corrigida para } 6,5 \% \text { de gordura } \\
\text { e } 5,8 \% \text { de protegida (kg/animal.dia) }\end{array}$} \\
\hline & & Controle & Gordura protegida & Controle & Gordura protegida & Controle & Gordura protegida \\
\hline \multirow{6}{*}{$\begin{array}{l}\text { Antes da } \\
\text { desmama }\end{array}$} & $1 \underline{\mathrm{a}}$ & $0,378 \mathrm{Ac}$ & $0,385 \mathrm{Ac}$ & $0,309 b$ & $0,241 b$ & $0,304 b$ & $0,245 b$ \\
\hline & $2 \underline{a}$ & 0,432 Abc & $0,440 \mathrm{Abc}$ & $0,227 b$ & $0,237 b$ & $0,236 b$ & $0,247 b$ \\
\hline & $3 \underline{a}$ & $0,451 \mathrm{Ab}$ & $0,453 \mathrm{Ab}$ & $0,226 b$ & $0,225 b$ & $0,240 \mathrm{~b}$ & $0,240 b$ \\
\hline & $4 \underline{a}$ & 0,439Abc & $0,455 \mathrm{Ab}$ & $0,210 \mathrm{~b}$ & $0,256 b$ & $0,222 b$ & $0,267 b$ \\
\hline & $5 \underline{a}$ & $0,463 \mathrm{Ab}$ & 0,435 Abc & $0,240 \mathrm{~b}$ & $0,249 b$ & $0,250 \mathrm{~b}$ & $0,260 \mathrm{~b}$ \\
\hline & $6^{\underline{a}}$ & $0,451 \mathrm{Ab}$ & $0,448 \mathrm{Ab}$ & $0,261 b$ & $0,274 b$ & $0,273 b$ & $0,285 b$ \\
\hline \multirow{3}{*}{$\begin{array}{l}\text { Após a } \\
\text { desmama }\end{array}$} & $7 \underline{a}$ & $0,554 \mathrm{Aa}$ & $0,563 \mathrm{Aa}$ & $0,471 \mathrm{a}$ & $0,390 a$ & $0,471 \mathrm{a}$ & $0,408 \mathrm{a}$ \\
\hline & $8^{\underline{a}}$ & $0,487 \mathrm{Bb}$ & $0,523 \mathrm{Aa}$ & $0,479 a$ & $0,452 \mathrm{a}$ & $0,472 \mathrm{a}$ & $0,450 \mathrm{a}$ \\
\hline & $9 \underline{a}$ & $0,426 \mathrm{Bbc}$ & $0,506 \mathrm{Aab}$ & $0,446 \mathrm{a}$ & $0,513 \mathrm{a}$ & $0,433 \mathrm{a}$ & $0,501 \mathrm{a}$ \\
\hline Média & & 0,453 & 0,468 & 0,319 & 0,315 & 0,322 & 0,323 \\
\hline
\end{tabular}

Médias seguidas de letras iguais, minúsculas nas colunas e maiúsculas nas linhas, não diferem $(\mathrm{P}<0,05)$ entre si pelo teste Tukey.

${ }^{1}$ Semana = (dias): 1 (1 ao 7), 2 (8 ao 14), 3 (15 ao 21), 4 (22 ao 28), 5 (29 ao 35), 6 (36 ao 42), 7 (43 ao 49$), 8$ (50 ao 56 ) е 9 (57 ao 60$)$. 
é de apenas 25\% na fração cisternal e $75 \%$ na fração alveolar, a qual é retida quando ocorre alguma falha na ejeção do leite.

Os teores de gordura do leite mantiveram-se semelhantes durante todo o período em que as ovelhas amamentaram seus cordeiros, para ambas as dietas. Assim que os cordeiros foram desmamados, os teores de gordura do leite dos animais mantidos com a dieta com gordura protegida tornaram-se menores entre as semanas 7 e 8 , mas, na nona semana, voltaram a ser semelhantes, o que comprova recuperação do teor de gordura na dieta com gordura protegida.

Embora a produção e composição do leite não tenham sido avaliadas por mais de 60 dias, tem-se observado na literatura que, com maiores períodos de lactação após a desmama do cordeiro, ocorre também expressivo aumento no teor de gordura do leite.

Em ovelhas no período de amamentação, Mckusick et al. (1999) avaliaram os sistemas misto e de desmama precoce, com e sem suplementação de gordura protegida, e observaram que os teores de gordura no leite foram menores nas ovelhas do sistema misto (2,51\%) - independentemente da suplementação, seguidas das ovelhas desmamadas precocemente sem suplementação (5,28\%) - e maior nas do grupo desmama precoce sob suplementação (6,52\%).

Cannas et al. (2002) verificaram que a utilização de gordura protegida na produção de leite ovino proporcionou aumento tanto na produção de leite quanto no teor de gordura do leite. Entretanto, isso ocorre muito mais rápido com o teor de gordura que com a produção.

Embora as correlações entre produção de leite e teores de gordura e proteína antes e após a desmama não tenham sido significativas (Tabela 5), segundo Ochoa-Cordero et al.
(2002), a produção de leite tem correlação negativa com a quantidade de sólidos totais, gordura e proteína e está diretamente relacionada à quantidade de lactose. De acordo com Bencini \& Pulina (1997), essa relação é válida na comparação entre as raças de alta e baixa produção e também entre animais de maior ou menor produção de leite em um rebanho e até mesmo quando se considera um mesmo animal durante os diferentes estágios de lactação.

Observaram-se correlações positivas significativas entre a produção de leite e as produções de gordura e proteína do leite , tanto antes quanto após a desmama, uma vez que, quanto mais leite é produzido, maior a produção em gramas de seus constituintes.

Não foi observada influência da dieta sobre os pesos ao parto e à desmama nem sobre o peso final (Tabela 6). As ovelhas de ambas as dietas ganharam peso entre os períodos do parto à desmama e ao final do experimento. Esses resultados corroboram os achados de Sklan (1992), que utilizou gordura protegida (5,6\%) na dieta de ovelhas Assaf por 90 dias de lactação e não encontrou diferenças entre as dietas e verificou ganho de peso durante todo o período experimental.

Os resultados observados neste estudo comprovam que, durante todo o período experimental, as ovelhas não entraram em balanço energético negativo, o que é comum entre espécies produtoras de leite. O fato de as ovelhas terem sido ordenhadas apenas uma vez ao dia após a desmama pode ter contribuído para esse resultado, uma vez que houve limitação da produção de leite, em decorrência da baixa frequência de ordenha e, portanto, da menor exigência nutricional do animal.

Teh et al. (1994), utilizando 0, 3, 6 e 9\% de gordura protegida na dieta de cabras, encontraram redução linear

Tabela 4 - Produção diária e teores médios de gordura e proteína durante todo o período experimental

\begin{tabular}{|c|c|c|c|c|c|c|c|c|c|}
\hline & \multirow[b]{3}{*}{ Sem $^{1}$} & \multicolumn{8}{|c|}{ Dieta } \\
\hline & & \multicolumn{2}{|c|}{ Gordura (g) } & \multicolumn{2}{|c|}{ Proteína（g) } & \multicolumn{2}{|c|}{ Gordura (g) } & \multicolumn{2}{|c|}{ Proteína（g) } \\
\hline & & Controle & $\begin{array}{c}\text { Gordura } \\
\text { protegida }\end{array}$ & Controle & $\begin{array}{c}\text { Gordura } \\
\text { protegida }\end{array}$ & Controle & $\begin{array}{c}\text { Gordura } \\
\text { protegida }\end{array}$ & Controle & $\begin{array}{c}\text { Gordura } \\
\text { protegida }\end{array}$ \\
\hline \multirow{6}{*}{$\begin{array}{l}\text { Antes da } \\
\text { desmama }\end{array}$} & $1^{\underline{a}}$ & 18,72 & 11,15 & 16,85 & 17,23 & $4,64 \mathrm{Aa}$ & $3,05 \mathrm{Ac}$ & 4,88 & 4,92 \\
\hline & $2 \underline{a}$ & 7,48 & 7,88 & 19,32 & 20,51 & $1,63 \mathrm{Ab}$ & $1,85 \mathrm{Ac}$ & 4,62 & 4,74 \\
\hline & $3 \underline{a}$ & 5,99 & 7,13 & 21,66 & 21,05 & $1,03 \mathrm{Ab}$ & $1,77 \mathrm{Ac}$ & 4,75 & 5,03 \\
\hline & $4 \underline{a}$ & 5,85 & 9,85 & 19,85 & 21,32 & $1,55 \mathrm{Ab}$ & $2,20 \mathrm{Ac}$ & 4,81 & 4,95 \\
\hline & $5 \underline{a}$ & 8,34 & 9,46 & 20,64 & 21,05 & 1,99Ab & $2,26 \mathrm{Ac}$ & 4,82 & 5,01 \\
\hline & $6 \underline{a}$ & 10,77 & 11,74 & 21,79 & 22,03 & $2,55 \mathrm{Ab}$ & $2,70 \mathrm{Ac}$ & 5,14 & 5,14 \\
\hline \multirow{3}{*}{$\begin{array}{l}\text { Após a } \\
\text { desmama }\end{array}$} & $7 \underline{a}$ & 28,80 & 19,32 & 27,77 & 30,55 & $5,88 \mathrm{Aa}$ & $3,59 \mathrm{Bc}$ & 5,48 & 5,66 \\
\hline & $8^{\underline{a}}$ & 32,51 & 27,66 & 24,24 & 26,21 & $7,08 \mathrm{Aa}$ & $5,37 \mathrm{Bb}$ & 5,49 & 5,44 \\
\hline & $9 \underline{a}$ & 30,98 & 35,22 & 20,38 & 24,46 & $7,21 \mathrm{Aa}$ & $7,47 \mathrm{Aa}$ & 5,15 & 5,32 \\
\hline Média & & 16,60 & 15,49 & 21,40 & 22,71 & 3,73 & 3,36 & 5,02 & 5,14 \\
\hline
\end{tabular}

Médias seguidas de letras iguais, minúsculas nas colunas e maiúsculas nas linhas, não diferem $(\mathrm{P}<0,05)$ entre si pelo teste de Tukey.

${ }^{1}$ Semana $=($ dias ): 1 (1 ao 7), 2 (8 ao 14), 3 (15 ao 21), 4 (22 ao 28), 5 (29 ao 35), 6 (36 aо 42$), 7$ (43 ao 49), 8 (50 ao 56 ) е 9 (57 ao 60$)$. 
Tabela 5 - Correlações entre produção de leite e teor e produção de gordura e proteína antes e após a desmama

\begin{tabular}{lcc}
\hline Constituinte do leite & $\begin{array}{c}\text { Produção de } \\
\text { leite antes }\end{array}$ & $\begin{array}{c}\text { Produção de } \\
\text { leite após }\end{array}$ \\
\hline Teor de gordura & 0,1812 & 0,0803 \\
Teor de proteína & $-0,2208$ & $-0,2127$ \\
Produção de gordura & $0,6088^{*}$ & $0,6838^{*}$ \\
Produção de proteína & $0,9697^{*}$ & $0,9383^{*}$ \\
\hline
\end{tabular}

* $\mathrm{P}<0,05$.

Tabela 6 - Desempenho de ovelhas alimentadas com dietas com e sem suplementação de gordura protegida

\begin{tabular}{lccc}
\hline Momentos & \multicolumn{2}{c}{ Pesos (kg) } & CV (\%) \\
\cline { 2 - 3 } & Controle & Gordura protegida & \\
\hline Ao parto & $54,27 \pm 9,27 \mathrm{~b}$ & $56,07 \pm 9,46 \mathrm{~b}$ & 16,97 \\
À desmama & $61,65 \pm 9,75 \mathrm{a}$ & $63,29 \pm 10,64 \mathrm{a}$ & 16,36 \\
$\begin{array}{l}\text { (45 dias) } \\
\text { Final (60 dias) }\end{array}$ & $62,78 \pm 9,19 \mathrm{a}$ & $63,92 \pm 9,85 \mathrm{a}$ & 15,04 \\
\hline
\end{tabular}

Médias seguidas de letras distintas nas colunas diferem entre si $(\mathrm{P}<0,05)$.

no ganho de peso, 110,3; 67,5; 53,3 e -39,6 g/dia, respectivamente. Também pode justificar os resultados encontrados neste trabalho o fato de as dietas terem suprido as exigências dos animais, dispensando a mobilização de gordura corporal para a produção de leite.

Cannas (1996) relatou que, em muitas raças de ovinos leiteiros, após os primeiros meses de lactação, as ovelhas tendem a utilizar os nutrientes mais para a deposição de gordura corporal que para a produção de leite. Esse mecanismo é mais evidente em ovelhas especializadas em produção de carne ou lã, não utilizadas para a produção de leite.

De acordo com Snowder \& Glimp (1991), a perda de peso de ovelhas durante as quatro primeiras semanas de lactação é mínima, mas pode aumentar com a persistência da lactação.

\section{Conclusões}

O uso de gordura ruminalmente protegida na dieta de ovelhas em sistema misto justifica-se quando o objetivo é aumentar a produção de leite após a desmama. A gordura protegida não influencia a variação de peso vivo das ovelhas do parto aos 60 dias de lactação.

\section{Agradecimentos}

À Fundação de Amparo à Pesquisa do Estado de São Paulo - FAPESP, pelo financiamento deste estudo.

\section{Literatura Citada}

BENCINI, R.; PULINA, G. The quality of sheep milk: a review. Australian Journal of Experimental Agriculture, v.37, p.485-504, 1997.

BOCQUIER, F.; CAJA, G. Production et composition du lait de brebis: effets de l'alimentation. Productions Animales, v.14, p.129-140, 2001.

BOCQUIER, F.; CAJA, G. Effects of nutrition on ewes' milk quality. In: GREAT LAKES DAIRY SHEEP SYMPOSIUM, 5., 1999, Wisconsin. Proceedings... Wisconsin: University of Wisconsin, 1999. p.98.

BRUCKMAIER, R.M.; BLUM, J.W. Oxytocin release and milk removal in ruminants. Journal Dairy Science, v.81, p.939-949, 1998.

CAJA, G.; BOCQUIER, F. Effects of nutrition on the composition of sheep's milk. Cahiers Options Méditerranéennes, v.52, p.59-74, 2000.

CANNAS, A. Nutrition of the dairy ewe. In: GREAT LAKES DAIRY SHEEP SYMPOSIUM, 2., 1996, Wisconsin. Proceedings... Wisconsin: University of Wisconsin, 1996. p.77.

CANNAS, A.; NUDDA, A.; PULINA, G. Nutritional strategies to improve lactation persistency in dairy ewes. In: GREAT LAKES DAIRY SHEEP SYMPOSIUM, 8., 2002, Wisconsin. Proceedings... Wisconsin: University of Wisconsin, 2002. p.182.

CHILLIARD, Y.; BOCQUIER, F. Effects of fat supplementation on milk yield and composition in dairy goats and ewes. In: INTERNATIONAL SYMPOSIUM LA QUALITA NELLE PRODUZINI DEI PICCOLI RUMINANTI, 5., 1993, Varese. Proceedings... Varese: Camera di Commercio Industria Artigiano Agricultura di Varese, 1993. p.78.

CHURCH, D.C. Alimentos y alimentacion del ganado. Tomo 1. Montevideo: Hemisferio Sur, 1984. 405p.

DEGEN, A.A.; BENJAMIN, R.W. Milk intake and growth rate of Awassi lambs sucking ewes grazing on natural pasture in the semi-arid Negev. Animal Science, v.76, p.455-460, 2003.

FOOD AND AGRICULTURE ORGANIZATION OF THE UNITED NATIONS - FAOSTAT. [2005]. Agricultural production. Disponível: <http://faostat.fao.org>. Acesso em: 7/12/2006.

FUERTES J.A.; GONZALO, C.; CARRIEDO, J.A. et al. Parameters of test day milk yield and milk components for dairy ewes. Journal Dairy Science, v.81, p.1300-1307, 1998.

GARGOURI, A.; CAJA, G.; SUCH, X. et al. Effect of suckling regime and number of milking per day on the performance of Manchega dairy ewes. Hungarian Journal of Animal Production, v.1, p.468-483, 1993 (suppl. 1).

HAENLEIN, G.F.W. Past, present, and future perspectives of small ruminant dairy research. Journal of Animal Science, v.84, p.2097-2115, 2001.

JENKINS, T.C.; PALMQUIST, D.L. Effect of fatty acids or calcium soaps on rumen and total nutrient digestibility of dairy rations. Journal Dairy Science, v.67, n.5, p.978-986, 1984.

LABUSSIÈRE, J. Importance, composition et signification des différentes fractions de lait obtenues successivement au cours de la traite mécanique des brebis. Annales de Zootechnie, v.18, p.185-196, 1969.

MARNET, P.G.; MCKUSICK, B.C. Regulation of milk ejection and milkability in small ruminants. Livestock Production Science, v.70, p.125-133, 2001.

MARNET, P.G.; NEGRÃO, J.A. The effect of a mixed-management system on the release of oxytocin, prolactin, and cortisol in ewes during suckling and machine milking. Reproduction Nutrition Development, v.40, p.271-281, 2000.

MCKUSICK, B.C.; THOMAS, D.L.; BERGER, Y.M. Effect of weaning system on commercial milk production and lamb growth of East Friesian dairy sheep. Journal of Dairy Science, v.84, p.1660-1668, 2001. 
MCKUSICK, B.C.; BERGER, Y.M.; THOMAS, D.L. Rumen protected bypass fat for dairy ewe commercial milk production. In: GREAT LAKES DAIRY SHEEP SYMPOSIUM, 5., 1999, Wisconsin. Proceedings... Wisconsin: University of Wisconsin, 1999. p.98.

NATIONAL RESEARCH COUNCIL - NRC. Nutrient requirements of sheep. 6.rev.ed. Washington, D.C.: National Academy of Science, 1985. 111p.

OCHOA-CORDERO, M.A.; HERNÁNDEZ, G.T.; ALFARO, A.E.O. et al. Milk yield and composition of Rambouillet ewes under intensive management. Small Ruminant Research, v.43, p.269-274, 2002.

PULINA, G.; SERRE, A.; CANNAS, A. et al. Determinazione e stima del valore energetico di latte di pecore di razza sarda. In: COngress SISVet, 43., 1989, Terrasini. Proceedings... Terrasini, 1989. p.1870.

REQUENA, R.; MOLINA, P.; FERNÁNDEZ, N. et al. Changes in milk and cheese composition throughout lactation in Manchega sheep. In: MILKING AND MILK PRODUCTION OF DAIRY SHEEP AND GOATS, 1999, Wageningen. Proceedings... Wageningen: EAAP Publication, 1999. p.95.

ROSSI, G.; SERRA, A.; PULINA, G. et al. L'utilizzazione di un alimento unico pellettato (Unipellet) nell'alimentazione delle pecore da latte. I. Influenza della grassatura e del livello proteico sulla produzione quanti-qualitativa di latte in pecore di razza Sarda. Zootecnica e Nutrizione Animale, v.17, p.23-34, 1991. SCHALM, O.W.; NOORLANDER, D. Experiments and observations leading to development of the California Mastitis Test. Journal of the American Veterinary Medical Association, v.130, p.199-204, 1957.

SKLAN, D. A note on production responses of lactating ewes to calcium soaps of fatty acids. Animal Production, v.55, p.288-291, 1992.

SNOWDER, G.D.; GLIMP, H.A. Influence of breed, number of suckling lambs, and stage of lactation on ewe milk production and lamb growth under range conditions. Journal of Dairy Science, v.50, p.597-603, 1991.

STELL, R.G.D.; TORRIE, J.H. Principles and procedures of statistic. A biometrical approach. 2.ed. New York: McGraw Hill, 1980. 633p.

TEH, T.H.; TRUNG, L.T.; JIA, Z.H. et al. Varying amounts of rumen-inert fat for high producing goats in early lactation. Journal of Dairy Science, v.77, p.253-258, 1994.

UNIVERSIDADE FEDERAL DE VIÇOSA - UFV. Sistema de análises estatísticas e genéticas - SAEG. Versão 9.0. Viçosa, MG, 2005. 301p. 